\title{
Substance Use in Pregnancy: Identifying Stigma and Improving Care
}

\author{
Andrea Weber' \\ Benjamin Miskle' \\ Alison Lynch' \\ Stephan Arndt ${ }^{2}$ \\ Laura Acion ${ }^{3}$ \\ 'Department of Psychiatry, University of \\ lowa Health Care, lowa City, IA, USA; \\ ${ }^{2}$ Department of Biostatistics, University \\ of lowa, lowa City, IA, USA; ${ }^{3}$ Universidad \\ de Buenos Aires - CONICET, Instituto \\ de Cálculo, Ciudad Autónoma de Buenos \\ Aires, Argentina
}

Correspondence: Andrea Weber Department of Psychiatry, University of lowa Health Care, 500 Newton Road, lowa City, IA, 52242, USA

$\mathrm{Tel}+\mid$ 319-384-80|4

Fax + I 319-384-7467

Email andrea-n-weber@uiowa.edu

\begin{abstract}
This review examines the impact of stigma on pregnant people who use substances. Stigma towards people who use drugs is pervasive and negatively impacts the care of substance-using people by characterizing addiction as a weakness and fostering beliefs that undermine the personal resources needed to access treatment and recover from addiction, including self-efficacy, help seeking and belief that they deserve care. Stigma acts on multiple levels by blaming people for having a problem and then making it difficult for them to get help, but in spite of this, most pregnant people who use substances reduce or stop using when they learn they are pregnant. Language, beliefs about gender roles, and attitudes regarding fitness for parenting are social factors that can express and perpetuate stigma while facilitating punitive rather than therapeutic approaches. Because of stigmatizing attitudes that a person who uses substances is unfit to parent, pregnant people who use substances are at heightened risk of being screened for substance use, referred to child welfare services, and having their parental rights taken away; these outcomes are even more likely for people of color. Various treatment options can successfully support recovery in substance-using pregnant populations, but treatment is underutilized in all populations including pregnant people, and more knowledge is needed on how to sustain engagement in treatment and recovery activities. To combat stigma when working with substance-using pregnant people throughout the peripartum period, caregivers should utilize a trauma-informed approach that incorporates harm reduction and motivational interviewing with a focus on building trust, enhancing self-efficacy, and strengthening the personal skills and resources needed to optimize health of the parent-baby dyad.
\end{abstract}

Keywords: stigma, pregnancy, substance use, opioid use, harm reduction

\section{Introduction}

Stigma is a dynamic process in which individuals and structures continuously engage in exchanges mediated by power, control, and domination. Stigma can influence the care of people at the individual, intrapersonal, and institutional level and can vary based on the condition that the stigma is applied. In the instance of substance use disorders (SUD), stigma frames addiction as a personal choice reflecting moral failing and deficiency in will power and can vary by substance. In this review, we will focus specifically on stigma related to substance use or SUD in pregnancy. ${ }^{1,2}$

Internalized stigma refers to the process in which a person using substances or with a SUD cognitively or emotionally absorbs negative messages or stereotypes about substance use and comes to believe them and apply them to themselves. This process can lead to anxiety, isolation, loss of self-love and facilitate people 
accepting injustice as deserved suffering. ${ }^{3,4}$ For people using drugs or with SUD, this may manifest in decreased engagement with support systems and avoiding medical care at the detriment to their overall health and wellness.

Interpersonal stigma is the mechanism whereby stigma is reenacted or manifested in interactions with other people. This form of substance-related stigma can be especially created or amplified during pregnancy. Pregnant people report increased or even new judgment and shame from those previously participatory or tolerant of their substance use, leading to further isolation. ${ }^{5}$ Such stigma can manifest even in those otherwise educated on SUD and their treatability, such as health-care workers. For example, in a 2016 national survey, $75 \%$ of primary care physicians were unwilling to have a person with opioid use disorder (OUD) marry into the family and $66 \%$ labeled people with OUD as dangerous. ${ }^{6}$
Institutional stigma, whether at the level of organizations, communities, or public policy, is the process in which an organization's negative attitudes, beliefs, and subsequent policies negatively effect, sometimes invisibly, how a condition or person group is treated in an establishment, such as a workplace or other institution. Despite increasing acceptance of SUD as a medical condition rather than moral failing, stigma against people who use drugs (PWUD), including pregnant people, remains written into laws, child welfare service policies, and how we allocate social services. Such stigma contributes to underinvestment in addiction treatment infrastructure as well as the discrimination in societal support, such as insurance benefits, employment, and housing. ${ }^{2}$

The Health Stigma and Discrimination Framework was developed by Stangl et al to conceptualize how stigma is operationalized and impacts various health and social outcomes. $^{7}$ Figure 1 is an adaption of this framework

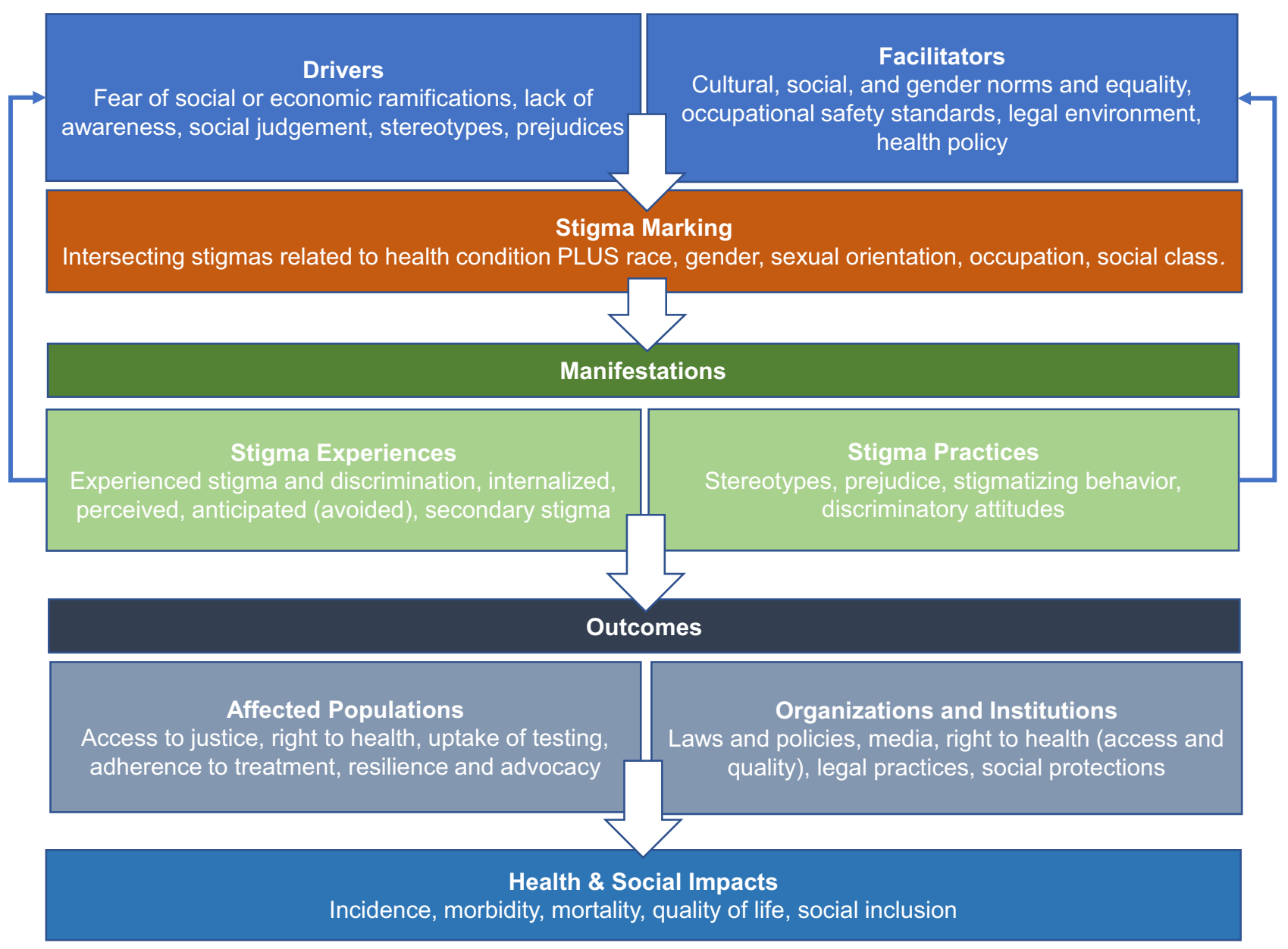

Figure I The Health Stigma and Discrimination Framework.

Notes: Reprinted from Stangl AL, Earnshaw VA, Logie CH, et al. The Health Stigma and Discrimination Framework: a global, crosscutting framework to inform research, intervention development, and policy on health-related stigmas. BMC Med. 2019;17(I):3I. Creative Commons license and disclaimer. Available from: http://creativecommons. org/licenses/by/4.0/legalcode ${ }^{7}$. 
specific to substance use and pregnancy, although many types of health and societal-related stigma often intersect. Table 1 provides examples on how stigma can impact care of pregnant PWUD at each level, as per this framework.

Parents with SUD report $49 \%$ greater odds of incurring stigma compared to non-parenting people with SUD. ${ }^{8}$ Some authors have posited that women who use drugs are more likely than men who use drugs to experience stigma, possibly related to proscribed gender norms. ${ }^{9}$ Substance use and how society treats PWUD is an example of how these gender norms are enforced to the detriment of parents. ${ }^{10}$ Being labeled as an "unfit" parent comes with serious consequences, such as incarceration and removal of parental rights. ${ }^{11}$ Such compounded stigmatization results in pregnant people avoiding substance use treatment and perinatal care, ultimately increasing harm to both parent and child..$^{8,12}$

Women are socially assigned the roles of mother, wife, and caregiver, which is especially true for those already with children. From a gender perspective, because an intoxicated woman is seen to be unable to fulfill her main societal roles, women with children who use drugs are more likely to experience stigmatization for violating this social construct. ${ }^{13}$ This amplified stigma towards pregnant people who use substances reflects intersectionality, a concept developed by Crenshaw whereby compared to non-pregnant people who use substances or pregnant people without substance use, those who are pregnant are judged more harshly, and experience more discrimination, bias, and marginalization. Along the same line, pregnant people of color who use substances experience even more discrimination and marginalization due to intersectionality of sexism and racism. ${ }^{14}$
Language can have significant impact on perpetuating stigma towards all PWUD, particularly during pregnancy. The American Society of Addiction Medicine (ASAM), other medical journals, and journalists with expertise reporting on substance use and SUD continue to combat the use of stigmatizing and pejorative language towards PWUD. ${ }^{15}$ For example, terms like "addict", "abuser", "alcoholic", "crack head", etc. should be avoided completely and replaced with "a person with" a specific substance exposure or use disorder. To pregnant populations who use drugs, terms like "addicted baby" should be replaced with "baby experiencing substance withdrawal." Precise and person-centered language is not only necessary to preserve humanity in our clinical spaces, but it has been shown to reduce the likelihood of clinicians utilizing punitive approaches towards PWUD. ${ }^{16,17}$ Table 2 summarizes the recommended terminology for various types of substance use based on the ASAM Policy Statements. ${ }^{15}$

To remain inclusive and patient-centered, we will refer to pregnant or birthing people to include the diverse populations that can conceive a child (eg, non-binary, gender non-conforming, etc.). Text that directly references women, pregnant women, or men refers to these terms as utilized by the research referenced. In addition, we refer to both chest and breast-feeding people to include all populations capable of lactation but may not identify as female or as having breasts.

For the remainder of this review, we will review the epidemiology of substance use in pregnancy, review various types and sources of harm associated with substance use in pregnancy, and introduce ways in which different institutions cause or perpetuate stigma as it relates to

Table I Example of How Each Level of Stigma Can Impact Outcomes for Pregnant Populations Using Substances

\begin{tabular}{|l|l|}
\hline $\begin{array}{l}\text { Level of } \\
\text { Stigma }\end{array}$ & Example Situation* \\
\hline Individual & A newly pregnant person believes they are a bad person because they use illegal substances and then delay seeking prenatal care. \\
\hline Interpersonal & $\begin{array}{l}\text { A newly pregnant person who uses drugs loses previously supportive friends or partners who may or may not also use drugs. } \\
\text { The loss of support causes isolation, depression, and increased risk for overdose. }\end{array}$ \\
\hline Organizational & $\begin{array}{l}\text { A healthcare institution obtains a urine drug screen in a newly pregnant person without consent. They respond to the positive } \\
\text { result by involving child welfare services but cannot provide further SUD care. As a result, the pregnant person loses trust in } \\
\text { their new medical provider and is lost to further perinatal care. }\end{array}$ \\
\hline Community & A substance use treatment facility does not offer a pregnant person evidence-based medications for the substance use disorder. \\
\hline Public Policy & $\begin{array}{l}\text { Criminalization of substance use and involvement of child welfare services in pregnancy decreases someone's engagement in } \\
\text { medical care, increasing morbidity and mortality of the substance use for the parent and child. }\end{array}$ \\
\hline
\end{tabular}

Note: *Example situations were generated based on the authors' clinical experiences. 
Table 2 Recommended Terms for Spectrum of Substance Use

\begin{tabular}{|l|l|}
\hline Recommended Terms* & Definition \\
\hline No Risk to Low Risk & $\begin{array}{l}\text { Amount below that identified as physically or psychosocially hazardous. Empirically derived for each substance when } \\
\text { possible. Difficult to define for unregulated drug supplies. }\end{array}$ \\
\hline Unhealthy Use** & Increases risk or likelihood of health consequences. \\
\hline Hazardous Use & Amount that has already led to health consequences. \\
\hline Harmful Use & \multicolumn{2}{|c|}{$\begin{array}{l}\text { Disease-referring terms } \\
\text { (SUD) }\end{array}$} & $\begin{array}{l}\text { Characterized by an inability to consistently abstain, impairment in behavioral control, craving, diminished recognition } \\
\text { of significant problems with one's behaviors and interpersonal relationships, and a dysfunctional emotional response. }\end{array}$ \\
\cline { 1 - 1 } Addiction &
\end{tabular}

Notes: *Stigmatizing terms to avoid: Misuse, abuse, inappropriate use, moderate drinking or moderate use. **Thresholds are defined by the amount and frequency of use or by the circumstances of use. Some of these thresholds are substance specified and others are not.

substance use in pregnancy. We will conclude with recommendations for how healthcare can reduce stigma and the subsequent harms to pregnant PWUD.

\section{Methods}

To conduct this narrative review, PubMed and Google Scholar databases were searched using the terms $<$ substance use $>$ AND $[<$ pregnancy $>$ OR $<$ peripartum $>$ OR $<$ perinatal $>$ ] along with $<$ stigma $>,<$ screening $>$, $<$ criminalization>, or <discrimination> between 1980 and August 2021. Inclusion criteria were articles in English and those focused on the forms and effects of stigma toward pregnant people who use any substance. Articles that were not available in English or were not focused specifically on pregnant people who use substances were excluded from the review.

\section{Epidemiology}

Many pregnant people reduce their substance use, including alcohol and nicotine products, during pregnancy. Of those who reduce their use, some completely abstain from substance use, while some continue to use substances less frequently or in smaller amounts. According to the National Survey on Drug Use and Health 2020 data report, tobacco continues to be the most widely used substance reported during pregnancy for non-institutionalized participants ages 15-44 years old, ranging from $14.9 \%$ of the pregnant population in 2015 to $9.6 \%$ in $2019 .{ }^{18}$ Tobacco is followed by alcohol and then substances characterized as "illicit drugs," such as cannabis, opioids, and cocaine. The categorization of a substance as "illicit" is an example of institutionalized stigma, given that criminalization of certain substances is often based on racism or politics, not necessarily based on public health or medical harms. ${ }^{19}$ Of the illicit drug use category, cannabis is by far the most widely reported substance used by pregnant populations, accounting for 112,000 of the 120,000 people reporting any illicit substance use. Despite cannabis being the most prevalent federally illicit substance used by pregnant populations, pregnant people still reported using significantly less cannabis than non-pregnant individuals in 2019 (5.4\% versus $14.7 \%$ ) with rates of overall cannabis use in non-pregnant women rising between 2015 and 2019. Past-month opioid use among pregnant women has not changed significantly between 2016 and 2019 and past-month cocaine use among pregnant women remains low. Pregnant women who reported past-year cannabis use were more likely to report other substance use, including cocaine, opioids, and alcohol. They were also more likely to report suicidal ideation, major depression, and other serious mental illness. This association between substance use and mental health comorbidity suggests that any substance use reported in pregnancy, including cannabis, should be met with curiosity by health-care providers and prompt screening of mental health needs, physical health needs, and other forms of support needed to reduce substance-related harm through the peri and postpartum periods.

\section{Screening for and Monitoring Substance Use in Pregnancy}

The rationale for screening pregnant people for substance use is that it may reduce the potential harms associated with substance use and improve parental and neonatal 
outcomes. Furthermore, pregnancy is a time when many are highly motivated for treatment. ${ }^{20}$ The potential benefits of screening must be weighed against the potential risks, including stigmatization, discrimination, legal charges, and the possibility of losing custody or parental rights. The act of screening for substance use itself presents an opportunity for the clinician to combat stigma by using personcentered, non-stigmatizing language and nonjudgmental and compassionate attitudes aimed at identifying and meeting needs. Yet screening, when done poorly, can also reinforce stigma and leave the person feeling judged or blamed. Screening without a clear protocol based on the response can also further biases informed by racism, sexism, and other forms of discrimination.

Because of potential benefits of screening, several organizations have issued recommendations regarding screening pregnant people for substance use (Table 3). The World Health Organization (WHO) recommends that health-care providers ask all pregnant people about their use of alcohol and other substances as early as possible in the pregnancy and at every antenatal visit. ${ }^{21}$ In the US, the Substance Abuse and Mental Health Services Administration (SAMHSA) recommends universal screening for substance use (including alcohol), brief intervention, and referral to treatment (SBIRT) as part of routine healthcare, including during pregnancy. ${ }^{22}$ The American College of Obstetrics and Gynecology (ACOG) recommends universal screening with a validated tool at the first prenatal visit. $^{23}$ The American Psychiatric
Association (APA) recommends screening pregnant and lactating people for substance use in a consistent and nondiscriminating way, with or without drug testing. ${ }^{24}$ The US Preventive Services Task Force (USPSTF) recommends asking all pregnant persons about tobacco use and unhealthy alcohol use (see Table 2 for the ASAM definition); USPSTF also recommends screening by asking questions about unhealthy drug use (defined by them as the use of illegal drugs and the nonmedical use of prescription psychoactive medications) in adults 18 years or older and adolescents, including pregnant and postpartum persons. ${ }^{25-27}$ ASAM issued a joint policy with ACOG in 2017 calling for universal verbal screening for substance use at the first prenatal visit with a coordinated multidisciplinary approach without criminal sanctions for positive screens. ${ }^{28}$

Acknowledging some of the potential harm that can be caused by testing for substance use during pregnancy, the ACOG recommends that specimen testing be performed only with the patient's consent and that a positive test not be a deterrent to care, a disqualifier for coverage under publicly funded programs, or the sole factor in determining family separation. ${ }^{29}$ An updated systematic review in 2020 by the Agency for Healthcare Research and Quality (AHRQ) for the USPSTF found no evidence on the benefits or harms of screening versus no screening for drug use. ${ }^{30}$ Considering the widespread recommendations and use of screening for substance use and the potential for harm, more research is needed to better understand the

Table 3 Summary of Organizational Guidelines and Position Statements About Substance Use in Pregnancy

\begin{tabular}{|c|c|}
\hline Organization & Guidelines or Position Statements \\
\hline World Health Organization (WHO) & $\begin{array}{l}\text { Guidelines for the identification and management of substance use and substance use disorders } \\
\text { in pregnancy, } 2014^{21}\end{array}$ \\
\hline $\begin{array}{l}\text { Substance Abuse and Mental Health Services } \\
\text { Administration (SAMHSA) }\end{array}$ & $\begin{array}{l}\text { Clinical Guidance for treating Pregnant and Parenting Women with Opioid Use Disorder and } \\
\text { Their Infants, } 2018^{22}\end{array}$ \\
\hline \multirow{2}{*}{$\begin{array}{l}\text { American College of Obstetrics and } \\
\text { Gynecology (ACOG) }\end{array}$} & Substance Use Disorder in Pregnancy, $2021^{29}$ \\
\hline & Opioid Use and Opioid Use Disorder in Pregnancy (Joint Opinion with ASAM), $2017^{23}$ \\
\hline American Psychiatric Association (APA) & $\begin{array}{l}\text { Assuring the Appropriate Care of Pregnant and Newly-Delivered Women with Substance Use } \\
\text { Disorders, December } 2016^{24}\end{array}$ \\
\hline US Preventive Services Task Force (USPSTF) & $\begin{array}{l}\text { Screening and Behavioral Counseling Interventions to Reduce Unhealthy Alcohol Use in } \\
\text { Adolescents and Adults: US Preventive Services Task Force Recommendation Statement, } 2018^{25}\end{array}$ \\
\hline $\begin{array}{l}\text { American Society of Addiction Medicine } \\
\text { (ASAM) }\end{array}$ & $\begin{array}{l}\text { Substance use, Misuse, and Use Disorders During and Following Pregnancy, with an Emphasis on } \\
\text { Opioids, } 2017^{28} \\
\text { Opioid Use and Opioid Use Disorder in Pregnancy (Joint Opinion with ACOG), } 2017^{23}\end{array}$ \\
\hline
\end{tabular}


outcomes and consequences, including stigma, related to screening for substance use, particularly in pregnancy.

Incorporating verbal questioning from a health-care provider during a clinical encounter to screen for substance use in pregnancy is acceptable to pregnant patients. $^{31}$ One study found that most pregnant patients were willing to honestly disclose their use of alcohol, tobacco, and drugs to their health-care provider when asked. ${ }^{31}$ Other studies have found self-report of substance use to be reliable when there are no negative consequences for truthfully reporting substance use, such as refusal of standard-of-care for medical conditions, legal consequences, or involvement of the child welfare system. ${ }^{32,33}$ These findings exemplify how punitive policies and stigmatizing attitudes can interfere with patient-provider communication and lead to incomplete or inaccurate history gathering.

Using screening tools can increase systematic information gathering while utilizing more consistent, deliberate language, potentially reducing the impact of stigma on screening and improving the ability to obtain health information from patients. Six screening instruments have been validated to screen for substance use in pregnancy. These include the 4Ps Plus/5Ps, Substance Use Risk Profile - Pregnancy, CRAFFT, NIDA Quick Screen, Wayne Indirect Drug Use Screener, and Drug Abuse Screening Tool (DAST) - 10. ${ }^{34-40}$ A study compared 5 of these self-report instruments (all but the DAST 10) by having 1200 pregnancy women complete each of the questionnaires and comparing the screening results with 30day calendar recall or urine analysis. ${ }^{37}$ They found that none of the tools had both high sensitivity and high specificity, and the area under the curve was low for nearly all measures, suggesting low accuracy.

Urine, blood, sweat, amniotic fluid, breath, oral fluids, and hair specimens from the pregnant person can be tested during pregnancy and at delivery to assess for substance use and neonatal substance exposure. In the neonate, meconium is the most analyzed matrix but urine, hair, blood, umbilical cord tissues, and placenta can also be analyzed for the presence of substances. ${ }^{41}$ When used, the role of specimen testing should be to monitor treatment goals, and positive testing should prompt treatment implementation or adjustment rather than discharge or punishment. Specimen testing performed only at delivery misses the opportunity to establish treatment and recovery during pregnancy and too often is used to justify removing the newborn from the parent's custody and care. This punitive approach fails to optimize chances for treatment and recovery, is based on stigma (eg, the belief that treatment does not work, or the person is not worthy of treatment), and reinforces stigma (eg, the belief that if the person has continued to use substances during pregnancy, they are not worthy of being a parent).

Over the past 30 years, the benefits and risks of universal screening for substance use in pregnancy have been debated in the literature. Potentially desirable consequences of universal screening may include improved initiation of SUD treatment and recovery support services, and possibly improved neonatal and maternal outcomes. Advocates for universal screening argue that it provides equitable surveillance, so provider biases, stigma, and other discriminations do not cause some populations to be disproportionately screened, and thus disproportionately impacted by the consequences of positive screens. Standardized (but not necessarily universal) screening protocols use specific patient characteristics to determine who is at risk for substance use during pregnancy and selectively screen those who have been deemed "high risk." Yet, these characteristics are usually biased towards people of color, those living in poverty, and those from non-traditional households. Roberts et al compared child welfare system (CWS) referrals over 3.5 years at 2 hospitals, one that implemented a protocol and one that did not. During the study period, the protocolized hospital referred 5 times more Black families to CWS than white families and did not reduce disparities in CWS referrals. ${ }^{42}$ This further illustrates the impact of intersecting stigma, such as substance use and race.

Regardless of risk-benefit analysis regarding screening for substance use in pregnancy, most pregnant people who receive prenatal care in the US are screened for substance use. A recent analysis found variability in prenatal substance use screening from state to state, but overall, 95\% of pregnant women in the US were asked about alcohol and tobacco use during prenatal care, and $80 \%$ were asked about drug use. ${ }^{43}$ The same report noted that states with laws that criminalize prenatal drug use as child abuse or neglect have lower rates of screening, while states that mandate screening for prenatal substance use had higher rates of screening. This illustrates a double-edge sword: screening for drug use where criminal penalties exist for a positive screen making it less likely screening occurs, thereby reducing potential criminal penalties. This reduced screening also means that individuals who may benefit from more support or evidence-based treatments for possible SUD may stay unrecognized due to the stigma in public policy. Individuals who were younger, less 
educated, unmarried, Black, non-Hispanic, publicly insured, had a history of smoking before pregnancy, or received inadequate prenatal care were more likely to be screened for one or more substances.

Stigma impacts how and when health-care providers (HCP) screen pregnant patients for substance use. Some lack skills or a process for screening and are concerned that asking about substance use may interfere with the patient-provider relationship. In addition, HCP may have their own biases about substance use and/or race and lack trust that the patient will provide accurate and honest information about their substance use. ${ }^{44}$

From a pregnant person's standpoint, potential adverse consequences of universal screening include involvement with CWS; receiving a stigmatizing label while navigating the healthcare system during pregnancy; risk of being charged with a crime; and the rational fear of having children removed or losing custody. Fear of screening for substance use in pregnancy, or fear of consequences due to a positive screen, have been reported anecdotally as reasons pregnant people may delay seeking prenatal care or avoid prenatal care altogether.

Such fear that positive substance use screening in pregnancy will have legal consequences is well-founded. In the US, substance use during pregnancy is considered child abuse under civil child welfare statutes in 23 states and the District of Columbia. Three states consider substance use during pregnancy as grounds for civil commitment. ${ }^{45}$ In 8 states, health-care professionals are required by law to test for prenatal drug exposure if they suspect drug use, and 25 states plus the District of Columbia require health-care professionals to report suspected prenatal drug use. ${ }^{45}$ Some states do not limit reporting requirements to illicit substance use and include alcohol use during pregnancy as reportable. Testing results can be used as evidence in child welfare and legal proceedings, meaning that current state policies make the healthcare system a potential "entry point" for pregnant people using substances into the carceral and CWS. ${ }^{46}$ Policies directing institutions to manage suspected or confirmed substance use in pregnancy as justification to report or deliver a patient to law enforcement effectively divorce treatment of SUD from health care. ${ }^{47}$ Ultimately, criminalizing substance use in pregnancy is counterproductive, as rather than improving outcomes for pregnancy and newborns, criminalization is associated with less prenatal care and increased rates of neonatal withdrawal syndromes. ${ }^{48}$ Furthermore, laws criminalizing substance use in pregnancy disproportionately impact people of color, people with less access to SUD treatment, and people with less access to economic resources. ${ }^{47}$

Universal screening for substance use in pregnancy is associated with increased disparities; it does not address associated risks of stigma, criminalization, and discrimination and it does not address the broader social and economic contexts in which pregnant people use substances. ${ }^{47}$ Due to these and other adverse effects described above, we cannot support universal screening of pregnant people for substance use.

\section{Substance Use Impact on Pregnancy Outcomes}

The impact of substance use on a pregnant person and the fetus varies based on multiple variables, including but not limited to dose, timing of use, route of use, and the source of the drug supply. For example, fetal alcohol spectrum disorder (FASD) has been associated with intrauterine exposure to alcohol, likely associated with dosing exposure, but it is unclear how much alcohol exposure ultimately contributes to FASD. In terms of timing, substances can have variable impact on pregnancy outcomes based on when during gestation they are utilized. Medical consequences of substance use, regardless of pregnancy status, can also vary by route of use. Stigma can limit someone's ability to transition to an alternative route safely, as they may be unsure where to access information or be experiencing new isolation due to new interpersonal stigma related to substance use in pregnancy (see above). Table 4 is a summary of different medical sequela of substance use based on route.

Much of the unintentional medical harm that can come from substance use with or without pregnancy is secondary to a rapidly changing, contaminated, and unregulated drug supply. Since 2013, deaths secondary to fentanyl and other synthetic opioid exposures have outnumbered those from prescription opioids and heroin. ${ }^{49}$ Much of this synthetic opioid exposure is not known to the substance-using population, who may rely on harm reduction organizations and community drug testing to determine its presence. ${ }^{50} \mathrm{New}$ contaminants, such as xylazine and designer benzodiazepines, are also increasing the rate of substance-related deaths. Stigma against PWUD limits policy changes that would greatly ameliorate these harms, such as decriminalization and legalization of all substances, universal drug testing, and availability of safe consumption sites. Places, such as Portugal, that have decriminalized all personal use of drugs have seen significant reductions in drug-related deaths and decreased transmission of HIV related to drug use. ${ }^{51}$ 
Table 4 Substance-Related Medical Sequela Based on Route of Use

\begin{tabular}{|l|l|}
\hline Route & Medical Sequela \\
\hline Ingestion & Increased risk of excessive dosing \\
\hline Insertion & Anal/vaginal irritation, increased susceptibility to sexually transmitted infections, viral hepatitis \\
\hline Snorting & Viral hepatitis, erosion of nasal passages, epistaxis, lung irritation \\
\hline Smoking & End-stage lung complications: Emphysema, bronchitis, cancer \\
\cline { 2 - 3 } & Oropharyngeal complications: Pipe burns, lacerations \\
\cline { 2 - 3 } & Viral hepatitis \\
\hline Injection & $\begin{array}{l}\text { Blood-borne infections, bacterial infections, local skin and soft tissue infections, acute and chronic thrombophlebitis, superficial venous } \\
\text { thrombosis }\end{array}$ \\
\hline All & Unintentional poisoning, death \\
\hline
\end{tabular}

Potential harm to the fetus includes both exposure to a contaminated substance as well as subsequent withdrawal from a substance at birth. The number of infants born to parents with OUD more than doubled between 1998 and 2011. ${ }^{52}$ Neonatal withdrawal syndrome (NWS) is a collection of physiological and neurobehavioral signs and symptoms associated with the removal of a substance that a newborn had been consistently exposed to in utero. ${ }^{22}$ Approximately $50-80 \%$ of infants exposed to persistent opioids in utero will develop neonatal opioid withdrawal syndromes (NOWS) with higher rates reported in rural regions. ${ }^{53}$ In utero exposure to amphetamines has been associated with increased risk of preterm birth, low birth weight, and small for gestational age. ${ }^{54}$ NWS is still often referred to as neonatal abstinence syndrome, but the inclusion of abstinence perpetuates stigma and decreases the medical perspective of the condition. Based on the Oxford English Dictionary, abstinence is defined as "sense relating to selfrestraint or forbearance" or "the practice or discipline of resisting self-indulgence; self-restraint." Such a term cannot be applied to a newborn infant unable to attend to its basic needs and its use further perpetuates the morality our society associates with substance use. ${ }^{55}$ While the stigma of NWS may be unique to a certain type or category of substance, it is important to remember that consistent in utero exposure to many different medications can also result in a withdrawal syndrome at birth, such as anti-depressants and anxiolytics; yet, these withdrawal syndromes do not carry the same stigma or legal and social consequences.

Studies that seek to clarify any effect substance use and/ or medications utilized to treat SUD have on offspring are often complicated by significant confounding variables, such as tobacco use and other environmental exposures. ${ }^{56,57}$ For example, a systematic review published by Lee et al concluded that children born to opioid-dependent mothers had worse neurodevelopmental outcomes compared to children born to non-opioid dependent mothers, but note that potential confounders such as other substance use, tobacco use, and prematurity were not accounted for and could also influence these outcomes. ${ }^{58}$ Another systematic review investigating the risk of congenital anomalies and other adverse effects in substance-exposed children concluded that although drug use during pregnancy may increase these risks, many confounders exist when evaluating substance-using populations and cannot be discounted. ${ }^{59}$ Research should continue to explore such impacts, but it is prudent for clinicians to communicate such limitations to patients and other health-care professionals when discussing potential treatment options or harm reduction interventions.

Drug-related deaths remain a common cause of parental mortality. In a retrospective, population-based cohort study following over 1 million women in California between 2010 and 2012, a total of 300 women died (rate 28.33 deaths per 100,000 -person year) and drug-related deaths were the second lead cause of death (3.68 per 100,000 person years). Drug-related deaths plus deaths by suicide in this population accounted for $18 \%$ of the total maternal mortality in this study. ${ }^{60}$ In a 2017 report from nine maternal mortality review committees, mental health and SUD were linked to $12.9 \%$ and $8.2 \%$ of pregnancy-related deaths, respectively. ${ }^{61}$ Given the individual, interpersonal, and institutional stigma against both substance use and mental illness, addressing such stigma may reduce barriers and the subsequent morbidity and mortality related to such conditions. 
The impacts of stigma regarding substance use and the peripartum time can extend past the initial patient or child into how we socially support different conditions. For example, mothers of children born with FASD have been rated as more different, more prone to disdain, and more responsible for the condition compared to mothers with serious mental illness, SUD, or jail experience. Using a fictional budget allocation task as a proxy of discrimination, this resulted in significantly lower budget allocation towards FASD service programs compared to other service programs. ${ }^{62}$ This stigma is encapsulated heavily into many policies under the War on Drugs in the US, which promote criminalization of substance use rather than addressing the medical and public health needs for this population.

In the US, the federal Child Abuse Prevention and Treatment Act (CAPTA) requires state policies mandating when CWS should be notified and includes infants born "substance-affected," but does not further define how or when this should be applied. ${ }^{63}$ State laws subsequently vary on how CWS monitors or requires people to report on people with peripartum substance use. Even within the same state, health-care institutions may also have variable policies on screening for and reporting any substance use in the peripartum period. As such, many health-care professionals and hospital-based social workers are poorly informed about their role. The process in which substance use may be suspected or identified in pregnancy may include pregnant people obtaining medications for addiction treatment (such as buprenorphine), from substance use history included in the medical record, from a non-medical record of substance use (such as a state-based prescription monitoring program), or positive and sometimes coercively obtained drug testing. The lack of clarification in the term "substance-affected" may mean that pregnant populations in recovery using opioid agonist treatment are at risk of being reported to CWS, disincentivizing people from actively seeking evidence-based treatment for OUD. Many of the decisions made by participants in the reporting process are largely up to the individual, which tends to protect those with the most privilege. People of color, poor people, unhoused, or those with nontraditional family structures are most likely to be scrutinized with interviews, drug testing, reports filed, and ultimately loss of custody. ${ }^{57}$ Confusion about legal obligations and stigma against historically excluded populations lead many health-care professionals to default to a role of policing, which undermines the confidentiality and trust that remains at the core of an effective and ethical patient-provider relationship. Such a conflict is addressed in a 2020 policy statement by ACOG entitled "Opposition to Criminalization or Individuals During Pregnancy and the Postpartum Period," which advocates for improving access to treatment for SUD rather than focusing on punitive measures carried out by the criminal legal system, including CWS. ${ }^{64}$ This statement advocates against laws, policies, or practices that test individuals and newborns for substances without consent. In this policy, ACOG opposes mandated or required drug testing, especially without informed consent, and advocates for practitioners to rely on self-reported screening and history only. This policy notes that lack of uniform (and we would add clear) policies about screening, testing, and reporting substance use encourages reliance on biases and racism as an entry way into the CWS. Harms to the parent-child dyad caused by involvement in the CWS, such as an increase in parental substance use, trauma, and worse health outcomes for children, are often not weighed against potential harm of parental substance use. ${ }^{65}$ The CWS often defaults to separation rather than focusing financial, medical, and societal resources into supporting the family.

Almost half of US states have laws that criminalize substance use during pregnancy as a form of child abuse or as grounds for civil commitment. ${ }^{45}$ According to an analysis of cases by Angelotta, these laws are closely linked to legislative and judicial attempts to treat fetuses as legally separate persons, often at the expense of recognizing the individual rights of the pregnant person. ${ }^{66}$ At the same time, many pregnant people who have a SUD lack access to SUD treatment due to multiple factors including absence of a treatment program in their community, their insurance does not cover SUD treatment, stigma and fear of reprisal if they disclose substance use, and lack of awareness of treatment availability or treatment effectiveness. Several studies have found that laws criminalizing substance use in pregnancy do not achieve intended outcomes (reduced substance use in pregnancy and reduced neonatal withdrawal syndromes) but rather people delay or avoid seeking prenatal care and substance use treatment altogether, due to fear of punishment such as involvement with CWS, loss or parental rights, or incarceration. The American Civil Liberties Union calls these laws "bad medicine and bad policy". ${ }^{67,68}$

Because there is no unified dataset that collects information on the number of pregnant people who use substances and are incarcerated in federal or state prisons in the US, it is unknown how many pregnant people are 
incarcerated annually due to substance use. ${ }^{69} \mathrm{~A}$ report by Amnesty International estimated between 500 and 1000 pregnant people were incarcerated in prison in the US on charges of child abuse or endangerment related to substance use since $2014 .{ }^{70}$ Likely many more pregnant people are under surveillance through probation, parole, drug courts, and other community-based corrections programs. Furthermore, while the Eighth Amendment guarantees incarcerated individuals access to health care such as prenatal care, incarceration does not necessarily guarantee access to SUD treatment. ${ }^{67}$ Even after they are released from incarceration, simply having been incarcerated inflicts its own stigma and loss of liberties, rendering them, according to Michelle Alexander (The New Jim Crow, 2010), a second-class citizen, where they cannot vote and it is legal to discriminate against them in housing, employment, food assistance, and other fundamental services. These injustices adversely impact the parent, child, and family thus continuing a cycle of stigma, discrimination, and disparities that passes from one generation to the next. $^{47,65,71}$

\section{Treatment of SUD in Pregnancy}

It has been estimated that between 1992 and 2012, only 4\% of pregnant people were admitted to substance use treatment programs. These people were more likely to identify as white, be older reproductive age, be college-educated, and have health insurance. ${ }^{72}$ In a recent qualitative study by Phillippi et al, trained female callers contacting providers of medications for OUD (MOUD) over a 10-state area were less likely to secure an appointment if they were pregnant and had state-funded insurance. ${ }^{73}$ In many cases, callers stating they were pregnant were informed that the program only treated non-pregnant populations. In a similar qualitative study, trained callers who were pregnant were less likely to secure an appointment with a buprenorphine provider compared to non-pregnant callers and over $25 \%$ of buprenorphine and methadone providers only scheduling callers for intake after the caller agreed to pay by cash, rather than accepting insurance. $^{74}$

Accessibility to different treatment programs that can accommodate an active pregnancy and other childcare is variable. For example, per JACHO and SAMHSA guidelines, the status as a pregnant person allows those seeking methadone to bypass days to week-long waits to initiate treatment. In one qualitative study published by Stone, this policy was met positively and contributed to participants engaging more enthusiastically with methadone programming. ${ }^{12}$ Yet, postpartum, many of these same participants interested in methadone treatment will again navigate long opioid treatment program (OTP) wait times. Outside of opioid treatment programming, active pregnancy or the need to provide childcare services while in treatment drastically decreases access to care. In the same qualitative study by Stone, pregnant people described only 1 treatment facility within a 100-mile radius of the study site that admitted pregnant participants or participants that would require childcare on site. Access to pregnancy and child-friendly residential programming is limited by many factors, including but not limited to: qualified support staff, legal responsibilities, medical support and/or available relationships with provides who can provide obstetric care, and cost. Yet, providing essential services to pregnant or parenting participants in a secure environment cannot be overstated. Residential programming for actively pregnant or parenting adults with childcare onsite is an opportunity to support recovery from SUD while building communication and parenting skills in real-time, with the support and supervision of trained staff. Such community supports can help lessen intergenerational trauma, create resiliency for participants entering a new phase of recovery with children (possibly infants), and support the health of active pregnancies, improving outcomes for both parent and child. Prenatal care in people using drugs can reduce the risk for prematurity, low birth weight, and small for gestational age outcomes and should be initiated as early as possible. ${ }^{75}$

Efforts should be made to increase access to substance use treatment programs that include on-site pregnancy, parenting, and child-related services, as these have been shown to improve child development outcomes. ${ }^{76}$ A systematic review of substance use treatment and HIV prevention programs focused on pregnant populations has shown that not only are such programs cost-effective, but even cost-saving. Area of cost-savings included decreased cost on neonatal intensive care service, shorter hospitalization for the parent-infant dyad, and decreased costs that may be related to involvement in the carceral system. ${ }^{77}$

Table 5 includes medications that are currently FDAapproved for alcohol, opioid, and tobacco/nicotine use disorders. For OUD, organizations such as ASAM, ACOG, and the WHO recommend the use of opioid agonist therapy over detoxification based on low detoxification completion rates, high return to use rates after detoxification, and limited data on maternal and neonatal outcomes. $^{23,78-80}$ In a recent systematic review, 
Table 5 Medications Approved for Substance Use Disorders by the US Food and Drug Administration (FDA)

\begin{tabular}{|l|l|}
\hline $\begin{array}{l}\text { Substance Use } \\
\text { Disorder }\end{array}$ & Medication \\
\hline \multirow{4}{*}{ Alcohol } & Naltrexone \\
\cline { 2 - 3 } & Acamprosate \\
\cline { 2 - 2 } & Disulfiram \\
\hline \multirow{4}{*}{ Opioid } & Methadone \\
\cline { 2 - 3 } & Buprenorphine \\
\cline { 2 - 2 } & Naltrexone \\
\hline \multirow{3}{*}{ Tobacco/Nicotine } & Varenicline \\
\cline { 2 - 2 } & Bupropion SR \\
\cline { 2 - 2 } & Nicotine replacement therapy \\
\hline
\end{tabular}

buprenorphine compared to methadone in pregnancy was associated with a lower risk of preterm birth, greater birth weight, and larger head circumference with no greater harm of buprenorphine to parent or baby. ${ }^{81}$ A 2020 Cochrane Review concluded that methadone and buprenorphine are likely similar in efficacy and safety in the treatment of OUD for pregnant patients and babies but noted that adequately powered randomized controlled trials to compare different treatments limits the strength of this conclusion. ${ }^{82}$ Many studies evaluating child neurodevelopment outcomes in methadone or buprenorphineexposed pregnancies are limited by poor control selection, as often the unexposed control group comparison does not include parents with the underlying disease for which the medication is being utilized (eg, OUD) ${ }^{83}$ Naltrexone remains poorly studied when utilized for OUD. In a retrospective cohort study from Australia, which compared obstetric outcomes in pregnant people treated with naltrexone implant versus oral methadone versus sublingual buprenorphine, naltrexone had a significant increase in birth rate compared to opioid agonist treatment and control with a similar rate of complication as compared to methadone and buprenorphine treatment groups. ${ }^{84}$

Research on the treatment of alcohol use disorders (AUD) with withdrawal and maintenance medications during pregnancy is limited. Medications for alcohol withdrawal typically consist of a benzodiazepine to prevent seizures and decrease discomfort associated with withdrawal symptoms. Current medications for AUD maintenance therapy, such as naltrexone, acamprosate, and disulfiram have been used to help prevent alcohol consumption Babies exposed to alcohol in utero are at an increased risk of fetal alcohol spectrum disorder (FASD). While not all infants exposed to alcohol during pregnancy will develop FASD, no safe consumption amount of alcohol has been identified. ${ }^{84}$ The 2019 World Federation of Societies of Biological Psychiatry (WFSBP) and International Association for Women's Mental Health guidelines do not currently recommend any pharmacologic therapy for AUD maintenance therapy. ${ }^{85}$ However, these guidelines and the WHO recommend benzodiazepines in cases of alcohol withdrawal to prevent possible negative effects on the parent and fetus, potentially in an inpatient facility to monitor the parent and fetus. ${ }^{21}$

Evidence on the benefits and risks of FDA-approved medications for tobacco and nicotine use disorders (nicotine replacement therapy (NRT), bupropion, and varenicline) are limited. Although pharmacotherapy such as NRT is associated with improved quit rates at 6 months or longer compared to minimal support or no intervention, there is limited evidence on effects of NRT in pregnant populations compared to placebo. ${ }^{86}$ Behavioral interventions have been shown to improve cessation rates in late pregnancy with minimal adverse effects. ${ }^{87}$ Five large cohort studies compared stillbirth, birth outcomes, and congenital anomalies in infants exposed to NRT, bupropion, varenicline, or ongoing tobacco/nicotine and did not find significant differences. ${ }^{86}$

The WHO currently does not recommend any pharmacological treatment for stimulant use disorders in those who are pregnant. ${ }^{21}$ In conjunction, there are currently no FDA-approved medications for stimulant use disorder overall. The WHO does recommend cognitive behavioral therapy (CBT) and contingency management for stimulant use disorders in pregnant patients.

Stigma contributes to low rates of prescribing evidence-based pharmacotherapy for various SUD. In a study of veterans with OUD, identifying as Black and/ or living in a rural community were associated with decreased odds of receiving medications for OUD. ${ }^{88}$ Between 1996 and 2014, admissions for pregnant people with OUD increased from $16.9 \%$ to $41.6 \%$ based on the Treatment Episode Data Set-Admissions (TEDS-A) database, but the proportion receiving MOUD remained stable at $50 \%$. In this cohort, being white, older, self-referred, outpatient, and without psychiatric comorbidity was associated with an increased rate of MOUD. ${ }^{89}$ Pregnancy exacerbates the impact of this stigma, as many prescribers 
otherwise knowledgeable may be less comfortable and/or willing to utilize such pharmacotherapy in pregnancy, given the weak evidence base. In addition, seeking treatment in an office setting for SUD in pregnancy is reduced by the morality placed on substance use in pregnancy as well as legal/societal consequences.

\section{Trauma-Informed Care for Substance Use in Pregnancy}

Given the high prevalence of trauma and neglect in populations with SUD, including pregnant populations, incorporating trauma-informed practices into health-care systems may decrease barriers to seeking care. In a review of 23 qualitative studies describing health-care encounters of pregnant and postpartum women with SUD, the majority were labeled as "conflictual," further differentiated as either judgmental, disparaging, scrutinizing, disempowering, or deficient in care. In contrast, encounters that were supportive were described as recoverybased, accepting, and effective in care. ${ }^{90}$ Although a broad review of creating and implementing a traumainformed practice is outside the scope of this review, general principles can start small. For example, recognizing that many behaviors observed in people with SUD have been cultivated as ways to deal with past and current negative experiences. For many, these behaviors have allowed them to survive. Yet, many of these observed behaviors serve as drivers and facilitators of stigma, perpetuating the image of PWUD as difficult, selfish, or bad patients. In recognizing the foundation of these behaviors in others, health-care providers must also recognize what they bring to an encounter and how these conscious and unconscious feelings may manifest in their verbal responses, nonverbal responses, and treatment recommendations. Providing trauma-informed care should never require disclosure of details from participants, especially if such systems do not have the personnel or expertise to manage such disclosures. Providing choices through each step of care provides more control to participants and increases engagement.

\section{Reducing Substance-Related Harms in Pregnant Populations}

History of substance use, mental health struggles, and the experience of interpersonal violence is associated with lower quality of life for pregnant populations and the presence of such factors should prompt aggressive support from institutions that interact with pregnant populations. ${ }^{91}$ Instead of acting on institutional and medical policies that increase stigma and harms towards pregnant people who use substances, we recommend incorporating management and treatment practices centered in collaboration, respect, acceptance, empowerment, and compassion that can reduce harms while increasing patient efficacy. Just as with other populations who use drugs, harm reduction in the peripartum population has been shown to improve health outcomes. Patient engagement and retention in prenatal services increases. Health outcomes for infants improve, specifically resulting in fewer preterm and lowweight births which also increases the likelihood that infants are discharged home with mother. Harm reduction principles have also been shown to increase breastfeeding rates and facilitate early attachment and healthy childhood development. ${ }^{57}$

In addition to medical care, many behavioral strategies can be utilized to promote wellness and reduce harm in pregnant populations using substances. For example, action planning, utilization of written materials, supported problem-solving, and other motivational interviewing techniques have been shown to be effective at reducing alcohol and substance use during pregnancy. ${ }^{92}$ Low to moderate quality evidence has not consistently shown a difference in outcomes comparing different types of psychosocial treatment modalities, assuming that all these modalities were provided in the presence of other comprehensive care options, such as pharmacological treatment (such as methadone), mental health counseling, transportation, and childcare. ${ }^{93}$ This emphasizes the overall point that any method of identifying substance use in the peri and postpartum period requires protocols and resources to exist for the support and treatment of those with SUD. It has been this lack of widely available resources which has resulted in recommendations against universal screening of non-alcohol, non-nicotine related substance use when further referral services are not identified. ${ }^{26}$

\section{Peripartum}

Regardless of substance use history, an estimated $17.3 \%$ of pregnant persons report experiencing mistreatment, including but not limited to verbal and physical abuse, loss of autonomy, discrimination, and failure of providers to meet standards of care. This risk of maltreatment is even greater for people of color and low socioeconomic status. ${ }^{94}$ Staying mindful of unconscious bias and how health-care institutions propagate this stigma can help reduce further 
harm to our pregnant population with SUD. Providing education and advocacy for pregnant populations to receive evidence-based treatments for SUD is crucial to promoting the health and wellness of the parent-baby dyad. For example, ensuring pregnant patients with alcohol, opioid, and nicotine use disorders have access to FDA-approved evidence-based medications. In addition to active medical treatment, educating pregnant populations on harm reduction based on the substance utilized can also have significant health impacts. For example, in a systematic review of 63 studies, authors concluded that alcohol reduction (but not necessarily abstinence) was associated with major benefits to parent and child, including reduced alcohol-related injury, improved cardiovascular functioning, pathology-confirmed liver recovery, decreased psychiatric symptoms or need for psychiatric hospitalization, and lower psychosocial stress levels. ${ }^{95}$

\section{Labor/Delivery}

People who use substances are often labeled as "drugseeking" and can be denied standard-of-care pain relief based on their substance use history. Even historical substance use or use disorders that have been documented, but not updated, in a pregnant person's medical chart can introduce stigma and limit access to quality pain control in the peripartum period. Uncontrolled pain, traumatization, and other forms of institutional stigma can decrease the quality of care provided, decrease the likelihood that birthing people will remain in the hospital for recommended aftercare, and reduce the likelihood that the parent and child will return for recommended well-baby exams and postpartum appointments. Establishing relationships of trust and support enables care in the moment, but also invests in the future care of both parent and child. Patients on opioid agonist treatment for OUD should be continued on their agonist therapy; this dose should not be expected to provide additional analgesia and additional pain should be managed with additional therapies or treatments. ${ }^{96}$

\section{Postpartum}

The rooming-in of parent and baby, family integration, and increased practitioner training in neonatal withdrawal have been associated with improved outcomes for babies with NWS, including reduced need for pharmacotherapy and shorter hospital stays. Implementation of these strategies can be limited by poor institutional assessment tools, limited breastfeeding promotion, and practitioner stigma. ${ }^{97}$ Patients previously maintained on medications for SUD or other mental and physical health conditions should be offered to resume such treatments, pending plans for breastfeeding and risk/benefit analysis. ${ }^{22}$ The postpartum period can be a highrisk period for return to substance use as well as death by overdose. Although active pregnancy can be highly motivating for many people with SUD to seek recovery and focus on health, some may return to substance use soon after delivery and this use may be more chaotic and high-risk. Overdose rates are highest 7-12 months after having baby, likely due to many factors such as changes in physiologic response to substance, loss of tolerance, loss of support systems, and hormonal changes common in the postpartum period. In addition, the probability that medications for OUD, such as methadone, will be discontinued in the first 6 months postpartum can be as high as 56\%, which can also increase overdose risk and worsen health outcomes. ${ }^{98}$ Although routes exist for medical insurance and social services for pregnant populations, some of these supports may be removed postpartum, decreasing access to care. Noncoercive contraception counseling should be completed with the option to receive a long-acting reversible contraceptive prior to leaving the hospital. ${ }^{57}$

\section{Lactation}

Breast or chest feeding has significant benefits for both the lactating parent and baby. ${ }^{99}$ The ACOG recommends that people stable on MOUD, not using illicit drugs, and have no other contraindications to breastfeeding should be actively supported in breastfeeding. ${ }^{100}$ For those parents with OUD on methadone treatment, chest feeding has been shown to reduce harm in NWS, such as decreasing the need for pharmacologic treatment in babies, shortening the length of neonatal hospitalization, and decreasing the overall severity of NWS. As such, breast and chest feeding should be supported for parents interested, regardless of utilization of MOUD, and may require additional people and resources to overcome barriers. ${ }^{101}$ The benefit associated with chest feeding in buprenorphine maintenance patients is unclear, possibly complicated by its poor oral bioavailability. Due to insufficient data, ACOG discourages cannabis use during lactation. Yet, providing education that cannabis peaks in concentration approximately 1 hour after consumption may help reduce harm by encouraging planning around use and lactation. ${ }^{102}$ Alcohol use during breastfeeding can limit milk production and impair child motor development. ACOG recommends lactating people consume no more than $0.5 \mathrm{mg}$ alcohol per $\mathrm{kg}$ body weight and to 
avoid breast or chest feeding for at least 2 hours after alcohol ingestion, depending on amount ingested. ${ }^{102}$

\section{Conclusions and Future Directions}

In this narrative review, we present a summary of the literature showing that substance use during pregnancy is associated with various levels of stigma and that stigma worsens outcomes for birthing populations while propagating harm to the next generation. The first limitation of this work is that we conducted a narrative review of the literature, acknowledging that a systematic review would yield stronger conclusions. Second, given that we restricted our search to articles in English and also because of our clinical background, most of the review focuses on stigma against substance use in pregnancy from a US-centric perspective that does not directly generalize internationally.

SUD and deaths by overdose remain one of the most crucial public health crises of our time, worsened by punitive policies that are seeded in stigma. Although more research is needed to clarify the most effective methods to combat stigma towards SUD and SUD in pregnancy, the following strategies should be implemented now:

1. Use person-first language when referring to people using substances.

2. Focus on systems-level causes of addiction, rather than focusing on individuals.

3. Emphasize and advocate for solutions to the negative effects of substance use, such as overdose prevention through harm reduction programming.

4. Implement policies and protocols that support families, facilitate parent-child attachment, and enhance the capacity of parents to care for their children.

All institutions that interact with pregnant and parenting populations should critically evaluate how they communicate and interact with populations who use drugs from their signage and online presence to the first direct person contact down to each person that works within the area. Health-care institutions can make great strides by focusing less on policing the pregnant populations who use drugs and focusing more on robust inclusivity, support, harm reduction, and multidisciplinary integration of all methods shown to improve outcomes for parent-child dyads exposed to substances.

\section{Disclosure}

Dr Benjamin Miskle reports stock options from Johnson \& Johnson, received speaker fees at the annual meeting from Iowa Pharmacists Association, outside the submitted work. The authors report no other conflicts of interest in this work.

\section{References}

1. Parker R, Aggleton P. HIV and AIDS-related stigma and discrimination: a conceptual framework and implications for action. Soc Sci Med. 2003;57(1):13-24. doi:10.1016/S0277-9536(02) 00304-0

2. McGinty EE, Barry CL. Stigma reduction to combat the addiction crisis - developing an evidence base. $N$ Engl J Med. 2020;382 (14):1291-1292. doi:10.1056/NEJMp2000227

3. Yanos PT, Lucksted A, Drapalski AL, Roe D, Lysaker P. Interventions targeting mental health self-stigma: a review and comparison. Psychiatr Rehabil J. 2015;38(2):171-178. doi:10.1037/prj0000100

4. Cunningham JA, Sobell LC, Chow VM. What's in a label? The effects of substance types and labels on treatment considerations and stigma. J Stud Alcohol. 1993;54(6):693-699. doi:10.15288/ jsa.1993.54.693

5. Cleveland LM, Bonugli RJ, McGlothen KS. The mothering experiences of women with substance use disorders. ANS Adv Nurs Sci. 2016;39(2):119-129. doi:10.1097/ ANS.0000000000000118

6. Kennedy-Hendricks A, Busch SH, McGinty EE, et al. Primary care physicians' perspectives on the prescription opioid epidemic. Drug Alcohol Depend. 2016;165:61-70. doi:10.1016/j. drugalcdep.2016.05.010

7. Stangl AL, Earnshaw VA, Logie CH, et al. The health stigma and discrimination framework: a global, crosscutting framework to inform research, intervention development, and policy on health-related stigmas. BMC Med. 2019;17(1):31. doi:10.1186/ s12916-019-1271-3

8. Stringer KL, Baker EH. Stigma as a barrier to substance abuse treatment among those with unmet need: an analysis of parenthood and marital status. J Fam Issues. 2018;39(1):3-27. doi:10.1177/0192513X15581659

9. Covington SS. Helping women recover: a comprehensive integrated treatment model. Alcohol Treat Quart. 2000;18(3):99-111. doi:10.1300/J020v18n03_09

10. Paeralta RL, Jauk D. A brief feminist review and critique of the sociology of alcohol-use and substance-abuse treatment approaches. Sociol Compass. 2011;5:882-897. doi:10.1111/ j.1751-9020.2011.00414.x

11. Linnemann T. Mad men, meth moms, moral panic: gendering meth crimes in the Midwest. Crit Criminol. 2009;18:95-110. doi:10.1007/s10612-009-9094-8

12. Stone R. Pregnant women and substance use: fear, stigma, and barriers to care. Health Justice. 2015;3:2. doi:10.1186/s40352015-0015-5

13. Worrall A. Women and Punishment: The Struggle for Justice. Willan Pub.; 2002.

14. Crenshaw K. Demarginalizing the Intersection of Race and Sex: A Black Feminist Critique of Antidiscimination Doctrine, Feminist Theory and Antiracist Politics. University of Chicago Legal Forum; 1989.

15. Saitz R, Miller SC, Fiellin DA, Rosenthal RN. Recommended use of terminology in addiction medicine. $J$ Addict Med. 2021;15 (1):3-7. doi:10.1097/ADM.0000000000000673

16. Kelly JF, Westerhoff CM. Does it matter how we refer to individuals with substance-related conditions? A randomized study of two commonly used terms. Int $J$ Drug Policy. 2010;21 (3):202-207. doi:10.1016/j.drugpo.2009.10.010

17. Kelly JF, Westerhoff C, Westerhoff C. Does our choice of substance-related terms influence perceptions of treatment need? An empirical investigation with two commonly used terms. J Drug Issues. 2010;40:805-818. doi:10.1177/002204261004000403

18. National survey on drug use and health 2019; 2020. Available from: https://datafiles.samhsa.gov/. Accessed July 14, 2021. 
19. Sherman E. Nixon's Drug War, an Excuse to Lock Up Blacks and Protestors, Continues. Forbes; 2016.

20. Mitchell MM, Severtson SG, Latimer WW. Pregnancy and race/ ethnicity as predictors of motivation for drug treatment. $\mathrm{Am}$ $J$ Drug Alcohol Abuse. 2008;34(4):397-404. doi:10.1080/ 00952990802082172

21. Committee WHOGR. Guidelines for Identification and Management of Substance Use and Substance Use Disorders in Pregnancy. ISBN: 9789241548731. World Health Organization; 2014.

22. Substance Abuse and Mental Health Services Administration. Clinical Guidance for Treating Pregnant and Parenting Women with Opioid Use Disorder and Their Infants. Rockville, MD Substance Abuse and Mental Health Services Administration; 2018 .

23. American College of Obstetricians and Gynecologists ASoAM. Opioid Use and Opioid Use Disorder in Pregnancy. American College of Obstetricians and Gynecologists ASoAM; 2017.

24. American Psychiatric Association. American Psychiatric Association Position Statement: Assuring the Appropriate Care of Pregnant and Newly-Delivered Women with Substance Use Disorders. American Psychiatric Association; 2016.

25. Curry SJ, Krist AH, Owens DK, et al. Screening and behavioral counseling interventions to reduce unhealthy alcohol use in adolescents and adults: US preventive services task force recommendation statement. JAMA. 2018;320(18):1899-1909. doi:10.1001/ jama.2018.16789

26. Krist AH, Davidson KW, Mangione CM, et al. Screening for unhealthy drug use: US preventive services task force recommendation statement. JAMA. 2020;323(22):2301-2309. doi:10.1001 jama.2020.8020

27. Krist $\mathrm{AH}$, Davidson $\mathrm{KW}$, Mangione $\mathrm{CM}$, et al. Interventions for tobacco smoking cessation in adults, including pregnant persons: US preventive services task force recommendation statement. JAMA. 2021;325(3):265-279. doi:10.1001/ jama.2020.25019

28. American Society of Addiction Medicine. Public Policy Statement on Substance Use, Misuse, and Use Disorders During and Following Pregnancy, with an Emphasis on Opioids. American Society of Addiction Medicine; 2017.

29. American College of Obstetricians and Gynecologists. Substance Use Disorder in Pregnancy. Available from: https://www.acog. org/advocacy/policy-priorities/substance-use-disorder-in-preg nancy. Accessed November 10, 2021.

30. Patnode C, Perdue LA, Rushkin M, O'Connor EA. Screening for Unhealthy Drug Use in Primary Care in Adolescents and Adults, Including Pregnant Persons: Updated Systematic Review for the U.S. Preventative Services Task Force. Rockville, MD: Agency for Healthcare Research and Quality; 2020.

31. Toquinto SM, Berglas NF, McLemore MR, Delgado A, Roberts SCM. Pregnant women's acceptability of alcohol, tobacco, and drug use screening and willingness to disclose use in prenatal care. Womens Health Issues. 2020;30(5):345-352. doi:10.1016/j.whi.2020.05.004

32. Day CC, Degenhardt L, Maher L, Maher L, Maher L. Reliability of heroin users' reports of drug use behaviour using a 24 month timeline follow-back technique to assess the impact of the Australian heroin shortage. Addict Res Theory. 2004;12 (5):433-443. doi:10.1080/16066350410001713231

33. Jackson CTC, Frisman LK, Essock SM, Essock SM. Validity of self-reported drug use among people with co-occurring mental health and substance use disorders. J Dual Diagn. 2005;1 (1):49-63. doi:10.1300/J374v01n01_05

34. (NIDA) NIoDA. Resource guide: screening for drug use in general medical settings. 2012.
35. Chang G, Orav EJ, Jones JA, Buynitsky T, Gonzalez S, Wilkins-Haug L. Self-reported alcohol and drug use in pregnant young women: a pilot study of associated factors and identification. $J$ Addict Med. 2011;5(3):221-226. doi:10.1097/ADM.0b013e318214360b

36. Chasnoff IJ, Wells AM, McGourty RF, Bailey LK. Validation of the 4P's Plus screen for substance use in pregnancy validation of the 4P's Plus. J Perinatol. 2007;27(12):744-748. doi:10.1038/sj. jp. 7211823

37. Ondersma SJ, Chang G, Blake-Lamb T, et al. Accuracy of five self-report screening instruments for substance use in pregnancy. Addiction. 2019;114(9):1683-1693. doi:10.1111/add.14651

38. Ondersma SJ, Svikis DS, LeBreton JM, et al. Development and preliminary validation of an indirect screener for drug use in the perinatal period. Addiction. 2012;107(12):2099-2106. doi:10.1111/j.1360-0443.2012.03982.x

39. Skinner HA. The drug abuse screening test. Addict Behav. 1982;7 (4):363-371. doi:10.1016/0306-4603(82)90005-3

40. Yonkers KA, Gotman N, Kershaw T, Forray A, Howell HB, Rounsaville BJ. Screening for prenatal substance use: development of the substance use risk profile-pregnancy scale. Obstet Gynecol. 2010;116(4):827-833. doi:10.1097/AOG.0b013e3181ed8290

41. Carlier J, La Maida N, Di Trana A, Huestis MA, Pichini S, Busardo FP. Testing unconventional matrices to monitor for prenatal exposure to heroin, cocaine, amphetamines, synthetic cathinones, and synthetic opioids. Ther Drug Monit. 2020;42 (2):205-221. doi:10.1097/FTD.0000000000000719

42. Roberts SC, Zahnd E, Sufrin C, Armstrong MA. Does adopting a prenatal substance use protocol reduce racial disparities in CPS reporting related to maternal drug use? A California case study. J Perinatol. 2015;35(2):146-150. doi:10.1038/jp.2014.168

43. Patel E, Bandara S, Saloner B, et al. Heterogeneity in prenatal substance use screening despite universal screening recommendations: findings from the Pregnancy Risk Assessment Monitoring System, 2016-2018. Am J Obstet Gynecol MFM. 2021;3 (5):100419. doi:10.1016/j.ajogmf.2021.100419

44. Oni HT, Buultjens M, Abdel-Latif ME, Islam MM. Barriers to screening pregnant women for alcohol or other drugs: a narrative synthesis. Women Birth. 2019;32(6):479-486. doi:10.1016/j. wombi.2018.11.009

45. Institute G. Substance use during pregnancy. State laws and policies web site; 2021. Available from: https://www.guttmacher. org/state-policy/explore/substance-use-during-pregnancy. Accessed September 8, 2021.

46. Perritt J. \#WhiteCoatsForBlackLives - addressing physicians' complicity in criminalizing communities. $N$ Engl $\mathrm{J}$ Med. 2020;383(19):1804-1806. doi:10.1056/NEJMp2023305

47. Haffajee RL, Faherty LJ, Zivin K. Pregnant women with substance use disorders - the harm associated with punitive approaches. $N$ Engl J Med. 2021;384(25):2364-2367. doi:10.1056/NEJMp2101051

48. Faherty LJ, Kranz AM, Russell-Fritch J, Patrick SW, Cantor J, Stein BD. Association of punitive and reporting state policies related to substance use in pregnancy with rates of neonatal abstinence syndrome. JAMA Netw Open. 2019;2(11):e1914078. doi:10.1001/jamanetworkopen.2019.14078

49. Mattson CL, Tanz LJ, Quinn K, Kariisa M, Patel P, Davis NL. Trends and geographic patterns in drug and synthetic opioid overdose deaths - United States, 2013-2019. MMWR Morb Mortal Wkly Rep. 2021;70(6):202-207. doi:10.15585/mmwr. $\mathrm{mm} 7006 \mathrm{a} 4$

50. Wallace B, van Roode T, Pagan F, et al. What is needed for implementing drug checking services in the context of the overdose crisis? A qualitative study to explore perspectives of potential service users. Harm Reduct J. 2020;17(1):29. doi:10.1186/ s12954-020-00373-4

51. Slade H. Drug decriminalisation in Portugal: setting the record straight. 2020. 
52. Maeda A, Bateman BT, Clancy CR, Creanga AA, Leffert LR. Opioid abuse and dependence during pregnancy: temporal trends and obstetrical outcomes. Anesthesiology. 2014;121 (6):1158-1165. doi:10.1097/ALN.0000000000000472

53. Villapiano NL, Winkelman TN, Kozhimannil KB, Davis MM, Patrick SW. Rural and urban differences in neonatal abstinence syndrome and maternal opioid use, 2004 to 2013. JAMA Pediatr. 2017;171(2):194-196. doi:10.1001/jamapediatrics.2016.3750

54. Ladhani NN, Shah PS, Murphy KE; Knowledge Synthesis Group on Determinants of Preterm LBWB. Prenatal amphetamine exposure and birth outcomes: a systematic review and metaanalysis. Am J Obstet Gynecol. 2011;205(3):219 e211-217. doi:10.1016/j. ajog.2011.04.016

55. Press OU. Oxford English Dictionary. Third ed. Oxford University Press; 2021.

56. Nelson LF, Yocum VK, Patel KD, Qeadan F, Hsi A, Weitzen S. Cognitive outcomes of young children after prenatal exposure to medications for opioid use disorder: a systematic review and meta-analysis. JAMA Netw Open. 2020;3(3):e201195. doi:10.1001/jamanetworkopen.2020.1195

57. National Harm Reduction Coalition AoPHR. Pregnancy and Substance Use: A Harm Reduction Toolkit. Health Research Board; 2020.

58. Lee SJ, Bora S, Austin NC, Westerman A, Henderson JMT. Neurodevelopmental outcomes of children born to opioid-dependent mothers: a systematic review and meta-analysis. Acad Pediatr. 2020;20(3):308-318. doi:10.1016/j. acap.2019.11.005

59. Viteri OA, Soto EE, Bahado-Singh RO, Christensen CW, Chauhan SP, Sibai BM. Fetal anomalies and long-term effects associated with substance abuse in pregnancy: a literature review. Am J Perinatol. 2015;32(5):405-416.

60. Goldman-Mellor S, Margerison CE. Maternal drug-related death and suicide are leading causes of postpartum death in California. Am J Obstet Gynecol. 2019;221(5):489e481-489 e489. doi:10.1016/j.ajog.2019.05.045

61. Deaths BUSCTRaPM. Report from nine maternal mortality review committees. 2018.

62. Corrigan PW, Lara JL, Shah BB, Mitchell KT, Simmes D, Jones KL. The public stigma of birth mothers of children with fetal alcohol spectrum disorders. Alcohol Clin Exp Res. 2017;41 (6):1166-1173. doi:10.1111/acer.13381

63. Wakeman S, Jordan A, Beletsky L. When Reimagining Systems Of Safety, Take A Closer Look At The Child Welfare System | Health Affairs Blog. Healthaffairs.org. Available from: https:// www.healthaffairs.org/do/10.1377/hblog20201002.72121/full/. Accessed November 10, 2021.

64. Gynecologists ACoOa. Opposition to Criminalization of Individuals During Pregnancy and the Postpartum Period. Gynecologists ACoOa; 2020.

65. Harp KLH, Oser CB. A longitudinal analysis of the impact of child custody loss on drug use and crime among a sample of African American mothers. Child Abuse Negl. 2018;77:1-12. doi:10.1016/j.chiabu.2017.12.017

66. Angelotta C, Appelbaum PS. Criminal charges for child harm from substance use in pregnancy. $J$ Am Acad Psychiatry Law. 2017;45(2):193-203.

67. Daniel R. Prisons neglect pregnant women in their healthcare policies. Prison policy initiative; 2019. Available from: prison policy.org/blog/2019/12/05/pregnancy/. Accessed September 8, 2021.

68. Union ACL, Ferguson V. City of Charleston: social and legal contexts; 2021. Available from: https://www.aclu.org/other/fergu son-v-city-charleston-social-and-legal-contexts?redirect=reproduc tive-freedom/ferguson-v-city-charleston-social-and-legalcontexts. Accessed August 27, 2021.
69. Paltrow LM, Flavin J. Arrests of and forced interventions on pregnant women in the United States, 1973-2005: implications for women's legal status and public health. $J$ Health Polit Policy Law. 2013;38(2):299-343. doi:10.1215/03616878-1966324

70. International Amnesty. Criminalizing pregnancy: policing pregnant women who use drugs in the USA. Amnesty International; 2017. Available from: amnestyusa.org/reports/criminalizingpregnancy-policing-pregnant-women-use-drugs-usa/. Accessed September 8, 2021.

71. Clarkson AF, Christian WM, Pearce ME, et al. The Cedar Project: negative health outcomes associated with involvement in the child welfare system among young Indigenous people who use injection and non-injection drugs in two Canadian cities. Can $J$ Public Health. 2015;106(5):e265-270. doi:10.17269/ cjph. 106.5026

72. Salameh TN, Hall LA. Depression, anxiety, and substance use disorders and treatment receipt among pregnant women in the United States: a systematic review of trend and population-based studies. Issues Ment Health Nurs. 2020;41(1):7-23. doi:10.1080/ 01612840.2019.1667460

73. Phillippi JC, Schulte R, Bonnet K, et al. Reproductive-age women's experience of accessing treatment for opioid use disorder: "we don't do that here". Womens Health Issues. 2021;31:455-461. doi:10.1016/j.whi.2021.03.010

74. Patrick SW, Richards MR, Dupont WD, et al. Association of pregnancy and insurance status with treatment access for opioid use disorder. JAMA Netw Open. 2020;3(8):e2013456. doi:10.1001/jamanetworkopen.2020.13456

75. El-Mohandes A, Herman AA, Nabil El-Khorazaty M, Katta PS, White D, Grylack L. Prenatal care reduces the impact of illicit drug use on perinatal outcomes. J Perinatol. 2003;23(5):354-360. doi:10.1038/sj.jp.7210933

76. Niccols A, Milligan K, Smith A, Sword W, Thabane L, Henderson J. Integrated programs for mothers with substance abuse issues and their children: a systematic review of studies reporting on child outcomes. Child Abuse Negl. 2012;36 (4):308-322. doi:10.1016/j.chiabu.2011.10.007

77. Ruger JP, Lazar CM. Economic evaluation of drug abuse treatment and HIV prevention programs in pregnant women: a systematic review. Addict Behav. 2012;37(1):1-10. doi:10.1016/j.addbeh.2011.07.042

78. Terplan M, Laird HJ, Hand DJ, et al. Opioid detoxification during pregnancy: a systematic review. Obstet Gynecol. 2018;131 (5):803-814. doi:10.1097/AOG.0000000000002562

79. Medicine ASoA. National practice guideline for the use of medications in the treatment of addiction involving opioid use; 2018. Available from: https://www.asam.org/docs/default-source/practicesupport/guidelines-and-consensus-docs/asam-national-practiceguideline-supplement.pdf. Accessed September 10, 2021.

80. World Health Organization. Community management of opioid overdose; 2014. Available from: http://apps.who.int/iris/bitstream/ 10665/137462/1/9789241548816_eng.pdf. Accessed September 10, 2021.

81. Zedler BK, Mann AL, Kim MM, et al. Buprenorphine compared with methadone to treat pregnant women with opioid use disorder: a systematic review and meta-analysis of safety in the mother, fetus and child. Addiction. 2016;111(12):2115-2128. doi:10.1111/add.13462

82. Minozzi S, Amato L, Jahanfar S, Bellisario C, Ferri M, Davoli M. Maintenance agonist treatments for opiate-dependent pregnant women. Cochrane Database Syst Rev. 2020;11:CD006318.

83. Monnelly VJ, Hamilton R, Chappell FM, Mactier H, Boardman JP. Childhood neurodevelopment after prescription of maintenance methadone for opioid dependency in pregnancy: a systematic review and meta-analysis. Dev Med Child Neurol. 2019;61(7):750-760. doi:10.1111/dmcn.14117 
84. Kelty E, Hulse G. A retrospective cohort study of obstetric outcomes in opioid-dependent women treated with implant naltrexone, oral methadone or sublingual buprenorphine, and non-dependent controls. Drugs. 2017;77(11):1199-1210. doi:10.1007/s40265-0170762-9

85. Thibaut F, Chagraoui A, Buckley L, et al. WFSBP (*) and IAWMH (**) guidelines for the treatment of alcohol use disorders in pregnant women. World J Biol Psychiatry. 2019;20(1):17-50. doi:10.1080/15622975.2018.1510185

86. Patnode CD, Henderson JT, Coppola EL, Melnikow J, Durbin S, Thomas RG. Interventions for tobacco cessation in adults, including pregnant persons: updated evidence report and systematic review for the US preventive services task force. JAMA. 2021;325(3):280-298. doi:10.1001/jama.2020.23541

87. Chamberlain C, O'Mara-Eves A, Porter J, et al. Psychosocial interventions for supporting women to stop smoking in pregnancy. Cochrane Database Syst Rev. 2017;2:CD001055.

88. Finlay AK, Harris AHS, Timko C, et al. Disparities in access to medications for opioid use disorder in the veterans health administration. J Addict Med. 2021;15(2):143-149. doi:10.1097/ ADM.0000000000000719

89. Short VL, Hand DJ, MacAfee L, Abatemarco DJ, Terplan M. Trends and disparities in receipt of pharmacotherapy among pregnant women in publically funded treatment programs for opioid use disorder in the United States. J Subst Abuse Treat. 2018;89:67-74. doi:10.1016/j.jsat.2018.04.003

90. Renbarger KM, Shieh C, Moorman M, Latham-Mintus K, Draucker C. Health care encounters of pregnant and postpartum women with substance use disorders. West J Nurs Res. 2020;42 (8):612-628. doi:10.1177/0193945919893372

91. Lagadec N, Steinecker M, Kapassi A, et al. Factors influencing the quality of life of pregnant women: a systematic review. BMC Pregnancy Childbirth. 2018;18(1):455. doi:10.1186/s12884-0182087-4

92. Fergie L, Campbell KA, Coleman-Haynes T, Ussher M, Cooper S, Coleman T. Identifying effective behavior change techniques for alcohol and illicit substance use during pregnancy: a systematic review. Ann Behav Med. 2019;53(8):769-781. doi:10.1093/abm/ kay085
93. Terplan M, Ramanadhan S, Locke A, Longinaker N, Lui S Psychosocial interventions for pregnant women in outpatient illicit drug treatment programs compared to other interventions. Cochrane Database Syst Rev. 2015;(4):CD006037. doi:10.1002/ 14651858.CD006037.pub3

94. Vedam S, Stoll K, Taiwo TK, et al. The giving voice to mothers study: inequity and mistreatment during pregnancy and childbirth in the United States. Reprod Health. 2019;16(1):77. doi:10.1186/ s12978-019-0729-2

95. Charlet K, Heinz A. Harm reduction - a systematic review on effects of alcohol reduction on physical and mental symptoms. Addict Biol. 2017;22(5):1119-1159. doi:10.1111/adb.12414

96. Jones HE, O'Grady K, Dahne J, et al. Management of acute postpartum pain in patients maintained on methadone or buprenorphine during pregnancy. Am J Drug Alcohol Abuse. 2009;35 (3):151-156. doi:10.1080/00952990902825413

97. MacVicar S, Kelly LE. Systematic mixed-study review of nonpharmacological management of neonatal abstinence syndrome. Birth. 2019;46(3):428-438. doi:10.1111/birt.12427

98. Wilder C, Lewis D, Winhusen T. Medication assisted treatment discontinuation in pregnant and postpartum women with opioid use disorder. Drug Alcohol Depend. 2015;149:225-231. doi:10.1016/j.drugalcdep.2015.02.012

99. Feltner C, Weber RP, Stuebe A, Grodensky CA, Orr C, Viswanathan M. Breastfeeding Programs and Policies, Breastfeeding Uptake, and Maternal Health Outcomes in Developed Countries. Rockville (MD): Agency for Healthcare Research and Quality; 2018.

100. Gynecologists ACoOa. Breastfeeding challenges. acog.org2021. 2021.

101. McQueen K, Taylor C, Murphy-Oikonen J. Systematic review of newborn feeding method and outcomes related to neonatal abstinence syndrome. J Obstet Gynecol Neonatal Nurs. 2019;48 (4):398-407. doi:10.1016/j.jogn.2019.03.004

102. Gynecologists ACoOa. Marijuana use during pregnancy and lactation. Obstet Gynecol. 2017;130:e205-209. doi:10.1097/ AOG.0000000000002354

\section{Publish your work in this journal}

Substance Abuse and Rehabilitation is an international, peerreviewed, open access journal publishing original research, case reports, editorials, reviews and commentaries on all areas of addiction and substance abuse and options for treatment and rehabilitation. The manuscript management system is completely online and includes a very quick and fair peer-review system. Visit http://www.dovepress com/testimonials.php to read real quotes from published authors. 